\title{
Optimum Design of the Underwater Discharge System Based on Surrogate Modeling
}

\author{
Jisang $\mathrm{Ha}$ \\ Department of Naval Architecture and Ocean Engineering, Seoul National University, Seoul, Republic of Korea \\ Myung-II Roh \\ Department of Naval Architecture and Ocean Engineering, And Research Institute of Marine Systems Engineering, \\ Seoul National University, Republic of Korea, miroh@snu.ac.kr

\section{Seung-Ho Ham} \\ Department of Naval Architecture and Marine Engineering, Changwon National University, Changwon, Republic of \\ Korea
}

Sung-Jun Lee

Department of Naval Architecture and Ocean Engineering, Seoul National University, Republic of Korea

Follow this and additional works at: https://jmstt.ntou.edu.tw/journal

Part of the Fresh Water Studies Commons, Marine Biology Commons, Ocean Engineering Commons, Oceanography Commons, and the Other Oceanography and Atmospheric Sciences and Meteorology Commons

\section{Recommended Citation}

Ha, Jisang; Roh, Myung-Il; Ham, Seung-Ho; and Lee, Sung-Jun (2021) "Optimum Design of the Underwater Discharge System Based on Surrogate Modeling," Journal of Marine Science and Technology. Vol. 29: Iss. 3, Article 9. DOI: $10.51400 / 2709-6998.1438$

Available at: https://jmstt.ntou.edu.tw/journal/vol29/iss3/9

This Research Article is brought to you for free and open access by Journal of Marine Science and Technology. It has been accepted for inclusion in Journal of Marine Science and Technology by an authorized editor of Journal of Marine Science and Technology. 


\title{
Optimum Design of the Underwater Discharge System Based on Surrogate Modeling
}

\author{
Jisang Ha ${ }^{a}$, Myung-Il Roh ${ }^{\mathrm{b}, *}$, Seung-Ho Ham ${ }^{\mathrm{c}}$, Sung-Jun Lee ${ }^{\mathrm{d}}$ \\ ${ }^{a}$ Department of Naval Architecture and Ocean Engineering, Seoul National University, 1 Gwanak-ro, Gwanak-gu, Seoul 08826, \\ Republic of Korea \\ ${ }^{b}$ Department of Naval Architecture and Ocean Engineering, and Research Institute of Marine Systems Engineering, Seoul National \\ University, 1 Gwanak-ro, Gwanak-gu, Seoul 08826, Republic of Korea \\ ${ }^{\mathrm{c}}$ Department of Naval Architecture and Marine Engineering, Changwon National University, 20 Changwondaehak-ro, Uichang-gu, \\ Changwon 51140, Republic of Korea \\ d Department of Naval Architecture and Ocean Engineering, Seoul National University, 1 Gwanak-ro, Gwanak-gu, Seoul 08826, \\ Republic of Korea
}

\begin{abstract}
Underwater vehicles are equipped with a device for discharging projectiles, called the underwater discharge system. Because these vehicles have limited space, many studies have attempted to reduce the volume of the underwater discharge system while improving its performance. However, owing to the characteristics of the system, the occupied volume and performance conflict with each other. Therefore, minimizing the occupied volume while satisfying the required performance criteria is the most significant requirement in the design stage. To address this, an optimization problem for the underwater discharge system was mathematically formulated and solved using multi-objective genetic algorithms. Additionally, we proposed a method of using the surrogate modeling technique to find an optimum solution quickly. Linear regression, radial basis functions, and artificial neural networks were compared to generate an appropriate surrogate model. To evaluate the applicability of the proposed method, it was applied to optimize the design of an underwater discharge system. The results demonstrate that the proposed method can be effectively utilized to obtain the optimum design of an underwater discharge system within an acceptable time.
\end{abstract}

Keywords: Underwater discharge system, Optimum design, Surrogate modeling, Multi-objective optimization

\section{Introduction}

\subsection{Research background}

$\mathrm{U}$ nderwater vehicles are equipped with a device for discharging projectiles in marine environments; this device is called the underwater discharge system (hereafter, discharge system). When an engineer designs the discharge system of underwater vehicles, the following issues are important: minimizing the volume occupied by the system, reducing the noise and vibration, and achieving the required performance.
Owing to the large number of design variables associated with discharge systems, it is difficult to manually select a design alternative that minimizes the occupied volume while satisfying the performance requirements. Therefore, optimization has been employed to determine an excellent design alternative for the discharge system.

To determine a design alternative through the optimization process, the formulation of an optimization problem and mathematical model of the discharge system are required. In this study, we formulated an optimization problem for a discharge system that comprises design variables, objective functions, and constraints. In addition, we

* Corresponding author.

E-mail addresses: ericx5@snu.ac.kr (J. Ha), miroh@snu.ac.kr (M.-I. Roh), shham@changwon.ac.kr (S.-H. Ham), ship99@snu.ac.kr (S.-J. Lee). 
Table 1. Related work

\begin{tabular}{llll}
\hline Related work & Optimization & Surrogate modeling method & Application \\
\hline Prebeg et al. [3] & $\mathrm{X}$ & $\begin{array}{l}\text { Polynomial regression, Kriging, Radial } \\
\text { basis function }\end{array}$ & Ship structural design \\
Baroutaji et al. [4] & $\mathrm{X}$ & Response surface & Design of circular tube \\
Patnaik et al. [5] & $\mathrm{X}$ & Regression, Artificial neural network & $\begin{array}{l}\text { Subsonic aircraft design } \\
\text { Mengistu and Ghaly [6] }\end{array}$ \\
& $\mathrm{O}$ (Genetic algorithms) & Artificial neural network & $\begin{array}{l}\text { Design of turbomachinery } \\
\text { blades }\end{array}$ \\
Gunnu and Moan [7] & $\mathrm{X}$ & Artificial neural network & Anchor-handling operation \\
\hline
\end{tabular}

constructed a mathematical model of the discharge system. However, the mathematical model requires significant processing time to calculate the projectile motion by solving the equations of motion. Because the mathematical model is calculated more than a thousand times during the optimization, the process is very time-consuming. One solution for this is to use surrogate modeling, which is a type of simplified model. The surrogate model allows us to obtain an optimum design within a shorter amount of time while maintaining accuracy. In the following sections, the mathematical model, the formulation of an optimization problem, and the surrogate models for the discharge system are described.

\subsection{Related work}

Several studies have been conducted on the mathematical model of the discharge system. Wang [1] presented theories and techniques for the discharge system of the linear pump type, including hydraulic accumulators. Tian [2] used genetic algorithms (GAs) to optimize the configuration of the discharge system introduced by Wang. In his optimization formulation, he used 10 design variables. However, some dependent variables were also set to design the variables, which further complicated the problem. Additionally, the discharge valve-opening profile, which had a significant influence on the results, was assumed to be fixed.

Meanwhile, owing to the complexity of mathematical models, it is challenging to calculate them accurately in the optimization problem. To solve this, several studies have been conducted in the engineering field to simplify and accelerate complex calculations through surrogate modeling. Surrogate modeling is a method that uses a simplified model, called a surrogate model, instead of a mathematical model, to derive the results with reduced computational cost while maintaining as much accuracy as possible. Table 1 shows several studies conducted in the engineering field to predict outcomes quickly using surrogate modeling.

Prebeg et al. [3] used surrogate models, such as polynomial regression, kriging, and radial basis function (RBF), to design the ship's structure. Baroutaji et al. [4] obtained a better design of a circular tube under quasi-static lateral loading using the response surface methodology. Patnaik et al. [5] used regression and artificial neural networks (ANNs) to develop surrogate models for the design of subsonic aircraft. Mengistu and Ghaly [6] optimized turbomachinery blades using the GA and surrogate modeling with an ANN to reduce the calculation time for computational fluid dynamics (CFD) analysis. Gunnu and Moan [7] proposed an ANN to develop a surrogate model for anchorhandling operations.

In this study, we formulated an optimization problem, including the mathematical model, for designing the discharge system and solved it with multi-objective GA. However, finding an optimized design using the mathematical model has a limitation in that it requires considerable computation

Table 2. Classification of underwater discharge systems.

\begin{tabular}{|c|c|c|c|c|}
\hline \multicolumn{3}{|c|}{ Type of discharge system } & Method & Characteristics \\
\hline \multicolumn{3}{|c|}{ Self-discharge system } & The projectile propels itself and discharges & The oldest type \\
\hline \multirow[t]{3}{*}{$\begin{array}{l}\text { Forced-discharge } \\
\text { system }\end{array}$} & Direct air & & $\begin{array}{l}\text { Compressed air flows into the tube and discharges the } \\
\text { projectile }\end{array}$ & $\begin{array}{l}\text { Vibration/noise due to the } \\
\text { discharge of compressed air } \\
\text { occurs at the discharge }\end{array}$ \\
\hline & $\begin{array}{l}\text { Hydraulic } \\
\text { discharge }\end{array}$ & $\begin{array}{l}\text { Linear } \\
\text { pump }\end{array}$ & Using hydraulic pressure to discharge a projectile & Occupies a large volume \\
\hline & & $\begin{array}{l}\text { Air turbine } \\
\text { pump }\end{array}$ & $\begin{array}{l}\text { Using hydraulic pressure generated by an air turbine } \\
\text { pump to discharge a projectile }\end{array}$ & $\begin{array}{l}\text { Requires the highest } \\
\text { technology but lowest } \\
\text { vibration/noise }\end{array}$ \\
\hline
\end{tabular}


time. Therefore, we carried out a literature survey on the applications of surrogate modeling used to replace mathematical models. For this purpose, we analyzed various surrogate models, such as linear regression, RBF, and ANNs, and selected the most appropriate one for optimum design of the discharge system.

The remainder of this paper is organized as follows. In Section 2, the theoretical background and mathematical model of the discharge system are presented. In Section 3, the formulation of the optimization problem of the discharge system and the optimization results of the problem based on the mathematical model are described. In Section 4, the surrogate modeling of the discharge system and the optimization results obtained are presented. Finally, in Section 5, this study is summarized, and the scope for future work is discussed.

\section{Underwater discharge system}

\subsection{Types of underwater discharge system}

The underwater discharge system can be categorized into two types: self-discharge and forceddischarge systems, as shown in Table 2 . In the case of a self-discharge system, a projectile is discharged by itself, while in the case of a forced-discharge system, it is discharged by the force from the discharge system.

The forced-discharge system can be divided into direct air and hydraulic discharge types. The direct air type injects compressed air directly into the discharge tube, and the projectile is discharged. The hydraulic discharge type discharges a projectile through hydraulic pressure without direct contact with air. The hydraulic discharge type, which was developed in the 1980s, produces relatively low noise and small pressure difference [8], and can be further divided into the linear pump type and air turbine pump type. As the linear pump type is relatively inexpensive and easy to develop compared with the air turbine pump type, it is currently being widely used. For this reason, the discharge system of the linear pump type was selected in this study.

The discharge system mainly comprises two parts: a pressure part and a discharging part. The pressure part comprises an oil tank, an oil pump, an accumulator, and a cutoff valve. The discharging part comprises a discharge valve, oil cylinder, oil cylinder piston, piston rod, water cylinder, water cylinder piston, water tank, and projectile discharge tube.

When the discharge system starts operation, the accumulated nitrogen expands and pushes the oil (Fig. $1-1)$. Here, Fig. 1-X means the part ' $X$ ' in Fig. 1 . The pushed oil flows into the oil cylinder and pushes the piston to the left (Figs. 1-2). The water cylinder piston connected by the piston rod also moves to the left, pushing the water cylinder's water into the water tank (Figs. 1-3). The water increases the pressure in the water tank, and the high-pressure water flows into the discharge tube. Finally, the projectile is discharged (Figs. 1-4).

\subsection{Mathematical model of the underwater discharge system}

The mathematical model of the piston rod and the projectile used in this study are based on Wang [1] and Tian [2]. The following five assumptions were made to calculate the discharging force of the projectile through the underwater discharge system, using a linear pump.

(a) All processes are insulation processes.

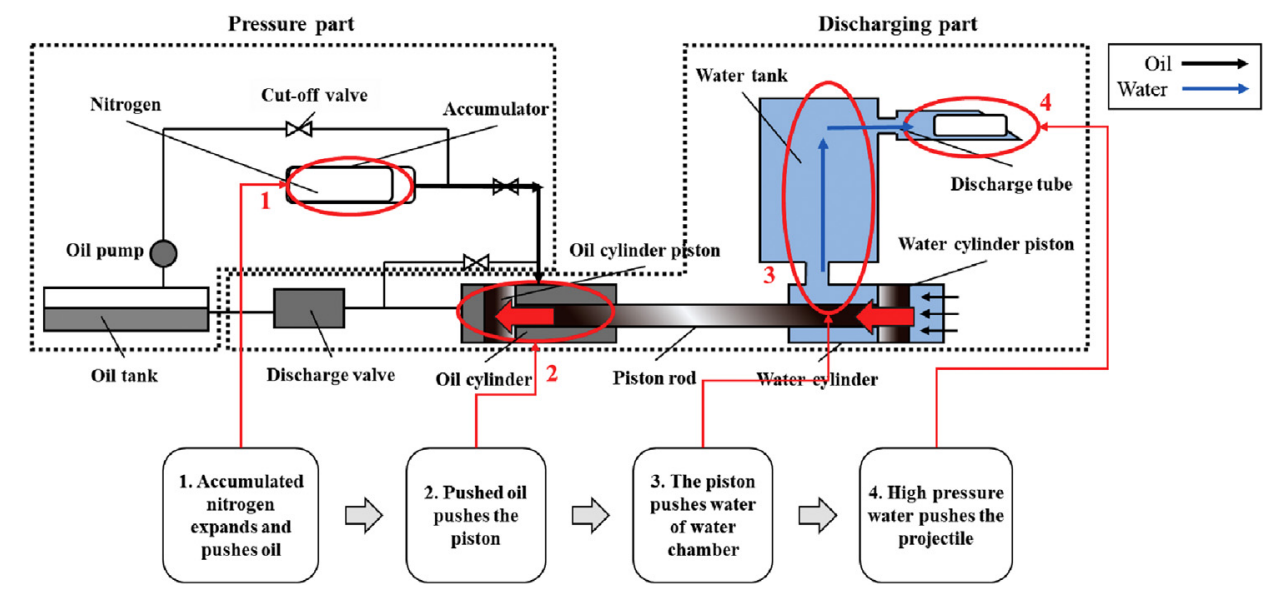

Fig. 1. Process of the linear pump discharge system. 


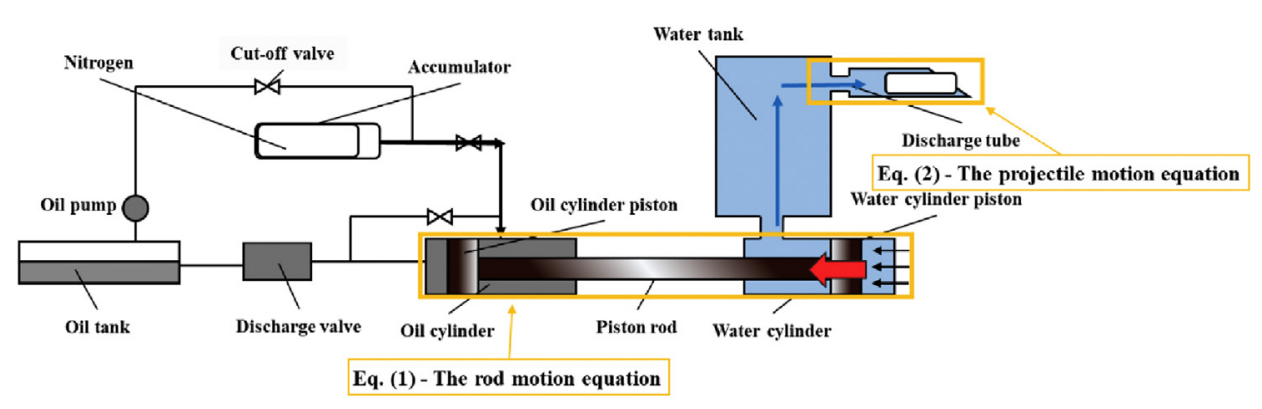

Fig. 2. The mathematical model for calculation discharging force.

(b) Each tank and tube are independent, and the pressure is uniform.

(c) The pressure difference between the oil cylinder and accumulator is ignored.

(d) The initial pressure of all parts in contact with seawater is in equilibrium with the external water pressure.

(e) External water pressure was constant.

The equations of motion of the piston rod and projectile are expressed as Eqs. (1) and (2), respectively: The piston rod and the projectile indicated by the corresponding equations of motion are shown in Fig. 2. Both equations are defined using Newton's second law:

$$
\begin{aligned}
& m_{p s t} a_{p s t}=P_{o c}\left(S_{\text {hydpst }}-S_{\text {rod }}\right)-P_{v} S_{\text {hyd } p s t} \\
& \quad-P_{w c}\left(S_{w t r p s t}-S_{r o d}\right)+P_{s e a} S_{w t r p s t}-F_{p s t} \\
& m_{p r} a_{p r}=-\left(P_{\text {tube }}-P_{\text {sea }}\right) S_{\text {tube }}-F_{\text {tube }}-A_{x}\left(v_{p r}+v_{\text {system }}\right)^{2} \\
& \quad-S_{\text {tube }} \rho v_{p r}{ }^{2}
\end{aligned}
$$

In Eq. (1), the piston has a mass $\left(m_{p s t}\right)$ and moves with acceleration $\left(a_{p s t}\right)$. The first term on the right-hand side of Eq. (1) represents the force exerted by the oil cylinder pressure on the right side of the oil cylinder piston. $P_{O C}$ is the pressure inside the oil cylinder, $S_{\text {hydpst }}$ is the cross-sectional area of the oil cylinder piston, and $S_{\text {rod }}$ is the cross-sectional area of the piston rod. The second term is the force exerted by the oil pressure exiting through the discharge valve from the left side of the oil cylinder piston. $P_{v}$ is the pressure in the space connected to the discharge valve. The third term refers to the force exerted by the water pressure inside the water cylinder. $P_{w c}$ is the pressure inside the water cylinder, and $S_{\text {wtrpst }}$ is the cross-sectional area of the water cylinder piston. The fourth term is the force inserted by the pressure exerted by the seawater on the right side of the water cylinder. $P_{\text {sea }}$ is the pressure of seawater at depth $H$. The last term $F_{p s t}$ is the frictional force that is generated when the piston moves and acts in the direction opposite to that of the motion.

In Eq. (2), $m_{p r}$ indicates the projectile mass, and $a_{p r}$ indicates the projectile acceleration. The first term on the right side of Eq. (2) is the force exerted by the pressure difference between the discharge tube and the outside. $P_{\text {tube }}$ is the pressure of the discharge tube. The second term is the frictional force $\left(F_{\text {tube }}\right)$, which causes the projectile to exit the tube. The third term refers to the resistance received by seawater, which is proportional to the square of the speed and the resistance coefficient $A_{x}$. The speed is expressed as the sum of the speed of the projectile $\left(v_{p r}\right)$ and that of the underwater discharge system $\left(v_{\text {system }}\right)$. The last term is the force exerted by the seawater occupying the space where the projectile went. $S_{\text {tube }}$ is the cross-sectional area of the projectile, $\rho$ is the density of water, and $v_{p r}$ is the projectile speed.

Eqs. (1) and (2) can be solved based on the following thermodynamic and kinetic equations: The properties of the oil cylinder can be determined through the adiabatic expansion process of the oil cylinder and the accumulator.

The volume of the oil cylinder $\left(V_{o c}\right)$ can be calculated as shown in Eq. (3).

$V_{o c}=V_{o c 0}+\left(S_{\text {hypdst }}-S_{\text {rod }}\right) x_{p s t}$

where $V_{o c 0}$ is the initial volume of the oil cylinder, and $x_{p s t}$ is the distance of the piston from the neutral point.

The relation between the volume of the oil cylin$\operatorname{der}\left(V_{o c}\right)$ and the pressure of the oil cylinder $\left(P_{o c}\right)$ can be expressed using Eq. (4).

$P_{o c} V_{o c}{ }^{k}=P_{o c 0} V_{o c 0}{ }^{k}$

where $P_{o c 0}$ is the initial pressure of the oil cylinder, $V_{o c 0}$ is the initial volume of the oil cylinder, and $k$ is the gas constant.

The slope of the pressure of the discharge valve, $P_{v}{ }^{\prime}$, can be calculated as shown in Eq. (5). 
$P_{v}^{\prime}=\left[S_{h y p d s t} v_{p s t}-q_{v}\right] \frac{\lambda_{y}}{V_{o c 0}-S_{h y d p s t} x_{p s t}}$

where $v_{p s t}$ is the speed of the piston, $q_{v}$ is the flow rate through the discharge valve, and $\lambda_{y}$ is the volume elastic modulus of hydraulic oil.

The flow rate through the discharge valve, $q_{v}$, can be calculated as shown in Eq. (6).

$q_{v}=C_{v} S_{v} \sqrt{\frac{2}{\rho_{y}}\left(P_{v}-P_{a c c}\right)}$

where $C_{v}$ is the flow coefficient of the hydraulic oil through the discharge valve, $S_{v}$ is the opening area of the discharge valve, $\rho_{y}$ is the density of the hydraulic oil, and $P_{a c c}$ is the pressure of the accumulator.

The slope of the pressure of the water cylinder, $P_{w c}{ }^{\prime}$, can be calculated as shown in Eq. (7).

$P_{w c}{ }^{\prime}=\left[\left(S_{w t r p s t}-S_{p s t}\right) x_{p s t}{ }^{\prime}-q_{w t i}\right] \frac{\lambda}{V_{w t 0}-\left(S_{w t r p s}-S_{p s t}\right) x_{p}}$

where $q_{w t i}$ is the flow rate into the water tank, $\lambda$ is the volume elastic modulus of water, and $V_{w t 0}$ is the initial volume of the water tank.

The flow rate into the water tank, $q_{\text {wtir }}$ can be calculated as shown in Eq. (8).

$q_{w t i}=C_{w c} S_{w c} \sqrt{\frac{2}{\rho}\left(P_{w c}-P_{w t}\right)}$ where $C_{w c}$ is the water flow coefficient between the water tank and the water cylinder, $S_{w c}$ is the opening area from the water cylinder to the water tank, $\rho$ is the density of water, and $P_{w t}$ is the pressure of the water tank.

The flow rate out of the water tank, $q_{w t o}$, can be calculated as shown in Eq. (9).

$q_{w t o}=C_{w t} S_{w t} \sqrt{\frac{2}{\rho}\left(P_{w t}-P_{t u b e}\right)}$

where $S_{w t}$ is the opening area between the water tank and the discharge tube.

The slope of the pressure of the water tank, $P_{w t}$, can be calculated as shown in Eq. (10).

$P_{w t}^{\prime}=\left[q_{w t i}-q_{w t o}\right] \frac{\lambda}{V_{w t}}$

where $q_{w t o}$ is the flow rate out of the water tank, and $V_{w t}$ is the volume of the water tank.

The slope of the pressure of the discharge tube, $P_{\text {tube }}{ }^{\prime}$, can be calculated as shown in Eq. (11).

$P_{\text {tube }}{ }^{\prime}=\left[q_{\text {tubei }}-q_{\text {tubeo }}-S_{\text {tube }} v_{p r}\right] \frac{\lambda}{S_{\text {tube }} x_{p r}+V_{\text {tube } 0}}$

where $q_{\text {tubei }}$ is the flow rate into the discharge tube, $q_{\text {tubeo }}$ is the flow rate out of the discharge tube, and $V_{\text {tube } 0}$ is the initial volume of the discharge tube.

The flow rate out of the discharge tube, $q_{\text {tubeor }}$ can be calculated as shown in Eq. (12).

Table 3. Definition of variables.

\begin{tabular}{lll}
\hline Item & Notation & Value \\
\hline Piston/Cylinder & & Design variable \\
\hline Diameter of oil cylinder piston & $D_{h y d p s t}$ & Calculated value \\
Cross-sectional area of oil cylinder piston & $S_{h y d p s t}$ & Design variable \\
Diameter of piston rod & $D_{\text {rod }}$ & Calculated value \\
Cross-sectional area of piston rod & $S_{r o d}$ & Design variable \\
Diameter of water cylinder piston & $D_{p w}$ & Calculated value \\
Cross-sectional area of water cylinder piston & $S_{w t r p s t}$ & $300.0 \mathrm{~kg}$ \\
Mass of piston & $m_{p s t}$ & Calculated value \\
Acceleration of piston & $a_{p s t}$ & Calculated value \\
Speed of piston & $v_{p s t}$ & Calculated value \\
Distance of piston & $x_{p s t}$ & Calculated value \\
Pressure of oil cylinder & $P_{o c}$ & Calculated value \\
Initial pressure of oil cylinder & $P_{o c 0}$ & Calculated value \\
Volume of oil cylinder & $V_{o c}$ & Calculated value \\
Initial volume of oil cylinder & $V_{o c 0}$ & $509.4 \mathrm{kPa}$ \\
Initial pressure inside water cylinder & $P_{w c 0}$ & Calculated value \\
Pressure inside water cylinder & $P_{w c}$ & 0.9800 \\
Flow coefficient of opening between water cylinder and water tank & $C_{w c}$ & 0.2265 m \\
Opening area between water cylinder and water tank & $S_{w c}^{2}$ \\
Frictional force coefficient of piston & $C_{p s t}$ & 0.3000 \\
\hline
\end{tabular}


Table 3. (continued)

\begin{tabular}{|c|c|c|}
\hline Item & Notation & Value \\
\hline \multicolumn{3}{|l|}{ Piston/Cylinder } \\
\hline \multicolumn{3}{|l|}{ Water tank } \\
\hline $\begin{array}{l}\text { Initial volume of water tank } \\
\text { Opening area between water tank and discharge tube } \\
\text { Coefficient of opening between water tank and discharge tube } \\
\text { Flow rate into water tank } \\
\text { Flow rate out of water tank } \\
\text { Pressure of water tank }\end{array}$ & $\begin{array}{l}V_{w t 0} \\
S_{w t} \\
C_{w t} \\
q_{w t i} \\
q_{w t o} \\
P_{w t} \\
\end{array}$ & $\begin{array}{l}12.50 \mathrm{~m}^{3} \\
0.2265 \mathrm{~m}^{2} \\
0.9800 \\
\text { Calculated value } \\
\text { Calculated value } \\
\text { Calculated value }\end{array}$ \\
\hline \multicolumn{3}{|l|}{ Projectile } \\
\hline $\begin{array}{l}\text { Mass of projectile } \\
\text { Diameter of projectile } \\
\text { Speed of projectile } \\
\text { Acceleration of projectile } \\
\text { Length of projectile } \\
\text { Initial position of projectile } \\
\text { Frictional force coefficient of projectile }\end{array}$ & $\begin{array}{l}m_{p r} \\
D_{p r} \\
v_{p r} \\
a_{p r} \\
l_{p r} \\
x_{p r 0} \\
C_{f g} \\
\end{array}$ & $\begin{array}{l}1500 \mathrm{~kg} \\
0.4500 \mathrm{~m} \\
\text { Calculated value } \\
\text { Calculated value } \\
5.500 \mathrm{~m} \\
0.5000 \mathrm{~m} \\
4.000 \times 10^{-2} \\
\end{array}$ \\
\hline \multicolumn{3}{|l|}{ Accumulator } \\
\hline $\begin{array}{l}\text { Initial accumulator pressure } \\
\text { Temperature of accumulator } \\
\text { Gas constant } \\
\text { Correction coefficient of accumulator } \\
\text { Minimum volume of accumulator } \\
\text { Maximum volume of accumulator } \\
\end{array}$ & $\begin{array}{l}P_{a c c 0} \\
T_{c} \\
K \\
C_{a} \\
V_{2} \\
V_{0}\end{array}$ & $\begin{array}{l}30.00 \mathrm{MPa} \\
20.00{ }^{\circ} \mathrm{C} \\
2.000 \\
1.170 \\
\text { Design variable } \\
\text { Calculated value } \\
\end{array}$ \\
\hline \multicolumn{3}{|l|}{ Discharge valve } \\
\hline $\begin{array}{l}\text { Coefficient of opening in discharge valve } \\
\text { Opening area of discharge valve } \\
\text { Pressure of discharge valve } \\
\text { Slope of pressure of discharge valve } \\
\text { Maximum opening area of discharge valve } \\
\end{array}$ & $\begin{array}{l}C_{v} \\
S_{v} \\
P_{v} \\
P_{v}^{\prime} \\
S_{v \max } \\
\end{array}$ & $\begin{array}{l}0.6500 \\
\text { Calculated value } \\
\text { Calculated value } \\
\text { Calculated value } \\
\text { Design variable } \\
\end{array}$ \\
\hline \multicolumn{3}{|l|}{ Discharge tube } \\
\hline $\begin{array}{l}\text { Length of discharge tube } \\
\text { Flow rate into discharge tube } \\
\text { Flow rate out of discharge tube } \\
\text { Cross-sectional area of discharge tube } \\
\text { Diameter of discharge tube } \\
\text { Initial volume of discharge tube } \\
\text { Pressure difference between discharge tube and water tank } \\
\text { Slope of the pressure of discharge tube } \\
\text { Gap between tube and projectile } \\
\text { Seawater coefficient } \\
\text { Opening area between discharge tube and water tank }\end{array}$ & $\begin{array}{l}L \\
q_{\text {tubei }} \\
q_{\text {tubeo }} \\
S_{\text {tube }} \\
D_{\text {tube }} \\
V_{\text {tube } 0} \\
\triangle P_{\text {tube }} \\
P_{\text {tube }} \\
\Delta \\
U \\
C_{\text {tube }} \\
\end{array}$ & $\begin{array}{l}7.500 \mathrm{~m} \\
\text { Calculated value } \\
\text { Calculated value } \\
0.2827 \mathrm{~m}^{2} \\
0.6000 \mathrm{~m} \\
\text { Calculated value } \\
\text { Calculated value } \\
\text { Calculated value } \\
2.0 \times 10^{-3} \mathrm{~m} \\
1.003 \times 10^{-6} \\
0.6500\end{array}$ \\
\hline \multicolumn{3}{|l|}{ External force } \\
\hline $\begin{array}{l}\text { Speed of underwater discharge system } \\
\text { Resistance coefficient } \\
\text { Volume elastic modulus of seawater } \\
\text { Volume elastic modulus of hydraulic oil } \\
\text { Density of seawater } \\
\text { Density of hydraulic oil } \\
\text { Activation depth of underwater discharge system } \\
\text { Pressure of seawater at depth } H \\
\text { Frictional force acting on piston }\end{array}$ & $\begin{array}{l}v_{\text {system }} \\
A_{x} \\
\Lambda \\
\lambda_{y} \\
\rho \\
\rho_{y} \\
H \\
P_{\text {sea }} \\
F_{p s t}\end{array}$ & $\begin{array}{l}5.000 \text { knots } \\
52.52 \\
1.99 \times 10^{9} \\
1.64 \times 10^{9} \\
1032.0 \mathrm{~kg} \mathrm{~m}^{-3} \\
857.0 \mathrm{~kg} \mathrm{~m}^{-3} \\
50.00 \mathrm{~m} \\
\text { Calculated value } \\
\text { Calculated value }\end{array}$ \\
\hline
\end{tabular}

$$
q_{\text {tubeo }}=\frac{\pi D_{\text {tube }} \delta^{3} \Delta P_{\text {tube }}}{12 u l_{\text {tube }}}
$$

where $D_{\text {tube }}$ is the diameter of the discharge tube, $\delta$ is the gap between the tube and the projectile, $\Delta P_{\text {tube }}$ is the pressure difference between the discharge tube and the water tank, $u$ is the seawater 


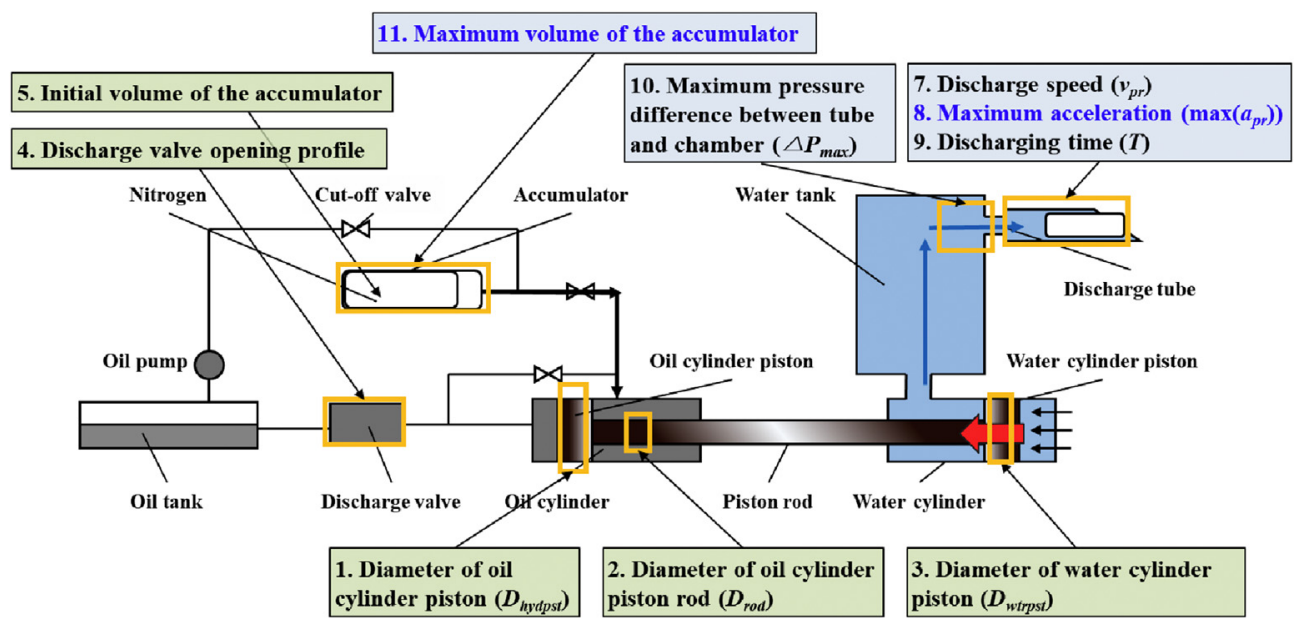

Fig. 3. Design variables and properties of the discharge system design.

kinetic viscosity coefficient, and $l_{\text {tube }}$ is the length of the tube.

To solve Eqs. (1)-(12), the basic design specifications of the discharge system and environmental information are needed. The input data of the simulation model are the basic design specifications of the underwater discharge system, the activation depth of the discharge system, the resistance coefficient, and the friction force acting on the projectile. Five of the design specifications (diameter of the oil cylinder piston $\left(D_{\text {hydpst }}\right)$, diameter of the piston rod $\left(D_{\text {rod }}\right)$, diameter of the water cylinder piston $\left(D_{\text {wtrpst }}\right)$, discharge valve-opening profile, maximum opening area of the discharge valve, and initial volume of the accumulator) are used as design variables. Other specifications, such as the projectile mass, discharge tube length, discharge tube specification, and speed of the underwater discharge system, are assumed based on the existing design. We assume the resistance coefficient, the frictional force acting on the projectile, and the initial accumulator pressure as generally used. The external sea pressure is also

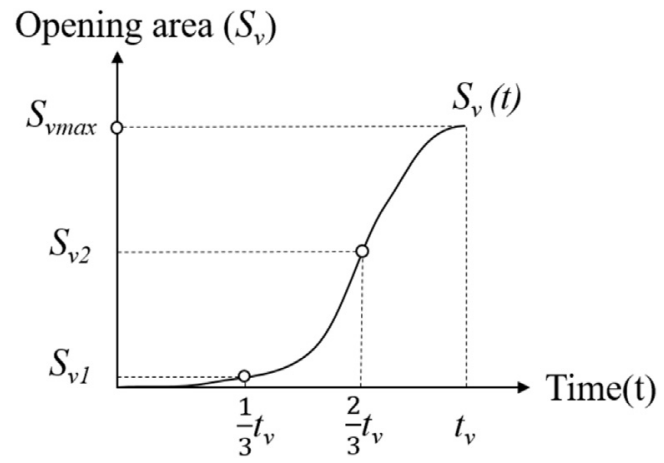

Fig. 4. Discharge valve-opening profile. calculated assuming the depth at which the underwater discharge system is normally active.

The variables introduced in Eqs. (1)-(12) are summarized in Table 3 . Some variables have already assigned constant values, while others are design variables or values calculated by the mathematical model.

In this study, numerical analysis was used to calculate the mathematical model. For numerical analysis, the implicit Runge-Kutta method [9] and variable time steps were used to provide stability in the calculation.

\section{Optimum design of the underwater discharge system}

This study aims to find the optimum design variables of the discharge system to minimize the occupied volume while satisfying the performance criteria. This section describes the design variables, objective functions, and constraints for optimizing the discharge system.

\subsection{Design variables}

Design variables represent the design specifications of the discharge system. Other variables of the design specifications, aside from the design

Table 4. Design variables for optimum design.

\begin{tabular}{ll}
\hline Design variables & Description \\
\hline$D_{\text {hydpst }}$ & Diameter of oil cylinder piston \\
$D_{\text {rod }}$ & Diameter of piston rod \\
$D_{p w}$ & Diameter of water cylinder piston \\
$S_{v 1}$ & Opening area at time $\mathrm{t}_{\mathrm{v}} / 3$ \\
$S_{v 2}$ & Opening area at time $2 \mathrm{t}_{\mathrm{v}} / 3$ \\
$S_{v \max }$ & Maximum opening area of discharge valve \\
$V_{2}$ & Minimum volume of accumulator \\
\hline
\end{tabular}




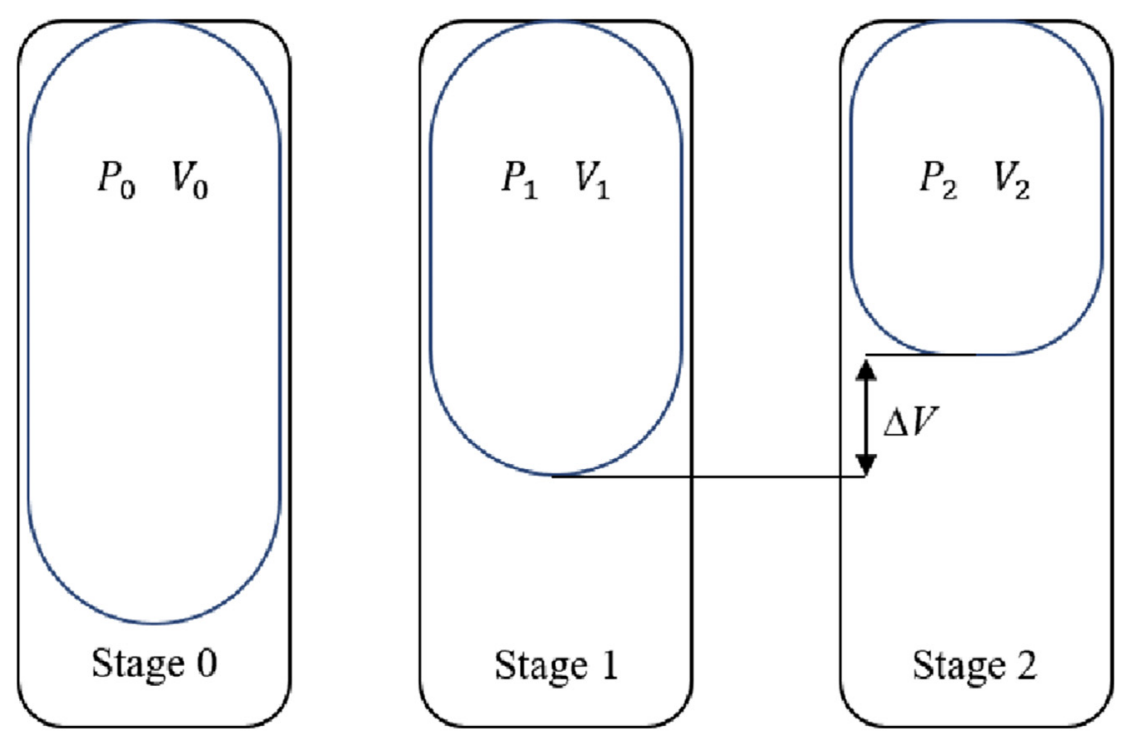

Fig. 5. Three states of the accumulator.

variables, are dependent values that can be determined by design variables or are determined by the environment. In this study, the diameter of the oil cylinder piston $\left(D_{\text {hydpst }}\right)$, diameter of the piston rod $\left(D_{\text {rod }}\right)$, diameter of the water cylinder piston $\left(D_{\text {wtrpst }}\right)$, opening profile of the discharge valve, maximum opening area of the discharge valve, and initial volume of the accumulator are selected as design variables, as shown in Fig. 3. In this figure, Fig. 3-X means the part ' $X$ ' in Fig. 3.

In the case of the discharge valve-opening profile (Figs. 3-4), we assume that the profile of the valve is a polynomial. To represent the valve profile, we take two points of the valve's polynomial profile as a design variable. The movement of the piston (Figs. 3-6), discharge speed (Figs. 3-7), maximum acceleration of the projectile (Figs. 3-8), discharge time (Figs. 3-9), maximum pressure difference between the tube and tank (Figs. 3-10), and maximum volume of the accumulator (Figs. 3-11) are properties that are used to determine the layout and performance of the underwater discharge system.

The layout of the system is closely related to the design variables. In terms of the layout of the underwater discharge system, the smaller the design variables (except $D_{\text {rod }}$ ), the more advantages the layout has. However, if the design variables are too small, they will not satisfy the required performance. Because the design variables have different scales, they should be normalized according to the following equation:

$\bar{x}_{i}=\frac{x_{i}-a}{b-a}$ where $\overline{x_{i}}$ is the normalized value of the design variables $x_{i}, a$ is the minimum value of the parameter, and $b$ is the maximum value of the parameter. The maximum value was determined by considering the layout of the system, and the minimum value was determined by considering the durability.

The conventional design assumes that the discharge valve opens linearly. Therefore, the opening area of the discharge valve is expressed using Eq. (14).

$S_{v}=S_{v \max } \times t / t_{v}$

where $t$ is the current time, $t_{v}$ is the time required for maximum opening, and $S_{v \max }$ is the maximum opening area of the discharge valve.

Unlike in the manual design, the opening profile is assumed to be modified because it has a significant influence on the motions of the piston rod and the projectile. In this study, the opening area $\left(S_{v 1}\right.$, $S_{v 2}$ ) of two of the free points and $S_{v \max }$ were determined as design variables of the discharge valveopening profile, as shown in Fig. 4.

The opening profile should be able to express bends sufficiently and should have minimal complexity to perform the optimization process efficiently. Since the start and end points and their slopes are given, the simplest curve, having three design variables, is the fifth-order polynomial. Therefore, we assume that the opening profile is a fifth-order polynomial, as shown in Eq. (15).

$S_{v}=S_{v \max } \times\left(A t^{5}+B t^{4}+C t^{3}+D t^{2}+E t+F\right) / t_{v}$

The design variables used for the optimum design are listed in Table 4. 
Table 5. Objective functions.

\begin{tabular}{lll}
\hline Objective functions & Type & Mathematical representation \\
\hline Maximum projectile acceleration & Minimize & $F_{1}=\max \left(a_{p r}(t)\right)$ \\
Maximum volume of the accumulator & Minimize & $F_{2}=V_{0}$ \\
\hline
\end{tabular}

The maximum volume of the accumulator can be calculated as follows.

\subsection{Objective functions}

The objective functions are important for minimizing the vibration related to the maximum acceleration of the profile and the volume occupied by the underwater discharge system. Therefore, the objective function is to minimize the maximum value of the acceleration of the projectile calculated by Eq. (2). The second objective function is to minimize the maximum volume of the accumulator, which constitutes a large portion of the system size. The following two objective functions were formulated:

Fig. 5 shows three different states of the accumulator, where $P_{0}, V_{0}, P_{1}, V_{1}, P_{2}$, and $V_{2}$ are the pressures and volumes of the accumulator at stages 0,1 , and 2 , respectively. Stage 0 represents the most massive volume of the accumulator. To calculate $V_{0}$, it is assumed that the process of changing between states is an adiabatic process. The minimum volume of the accumulator, $V_{2}$, and the pressure of the accumulator at that stage, $P_{2}$, are given. In the adiabatic process, Eqs. (16) and (17) can be used [10].

$V_{1}=V_{0}\left(P_{0} / P_{1}\right)^{1 / k}$

$V_{2}=V_{0}\left(P_{0} / P_{2}\right)^{1 / k}$

For the energy storage purpose of the accumulator, we assumed that the pressure of the accumulator at state 0 is $90 \%$ of the pressure at state 1, as shown in Eq. (18) [10]:

$P_{0}=0.9 P_{1}$

The volume change of the accumulator due to the piston motion is shown in Eq. (19).

$\Delta V=S_{\text {hydpst }} \times$ Stroke

In the adiabatic process, the maximum volume of the accumulator can be calculated as shown in Eq. (20).

$V_{0, \text { ideal }}=\frac{\Delta V}{\left\{\left(P_{0} / P_{1}\right)^{1 / k}-\left(P_{0} / P_{2}\right)^{1 / k}\right\}}$

To correct the differences between the ideal and actual conditions, we use Eq. (21).

$V_{0, \text { real }}=C_{a} \times V_{0, \text { ideal }}$ where $C_{a}$ is the correction coefficient of the accumulator.

\subsection{Constraints}

The performance requirements of the projectile should be considered as constraints. If the discharge speed does not satisfy the requirements, the design variables must be changed. The maximum acceleration of the projectile and the pressure difference between the discharge tube and water tank should be below a specific value to prevent damage caused to the projectile. Additionally, the discharge valve should have a reasonable profile. The following constraints are formulated to consider these aspects.

To satisfy the required performance, the discharge speed determined by Eq. (2) should not be less than the required value. We set the constraint to limit the projectile discharge speed to a specific range, as shown in Eq. (22) [11]:

$v_{p r}<11[\mathrm{~m} / \mathrm{s}]$

It is necessary to prevent projectile damage and noise/vibration during discharge from the discharge system. The constraint uses the maximum value of the acceleration determined by Eq. (2). We set the constraint to limit the maximum acceleration of the projectile to a specific range, as shown in Eq. (23) [11]:

$\max \left(a_{p r}\right)<8 g\left(=78.4\left[\mathrm{~m} / \mathrm{s}^{2}\right]\right)$

The pressure difference in the discharge tube is also indicated as a cause of noise and vibration. To prevent noise and vibration, we set the constraint to limit the maximum pressure difference to a specific range, as shown in Eq. (24) [2]:

Table 6. Comparison of design variables between manual and optimum designs.

\begin{tabular}{lll}
\hline Design variables & Manual design & Optimization \\
\hline$D_{\text {hydpst }}$ & $0.2173 \mathrm{~m}$ & $0.1500 \mathrm{~m}$ \\
$D_{\text {rod }}$ & $0.1959 \mathrm{~m}$ & $0.1007 \mathrm{~m}$ \\
$D_{p w}$ & $1.026 \mathrm{~m}$ & $1.100 \mathrm{~m}$ \\
$S_{v 1}$ & - & 0.2020 \\
$S_{v 2}$ & - & 0.6390 \\
$S_{v \max }$ & $7.900 \times 10^{-3} \mathrm{~m}^{2}$ & $1.000 \times 10^{-4} \mathrm{~m}^{2}$ \\
$V_{2}$ & $2.209 \times 10^{-2} \mathrm{~m}^{3}$ & $8.887 \times 10^{-4} \mathrm{~m}^{3}$ \\
\hline
\end{tabular}




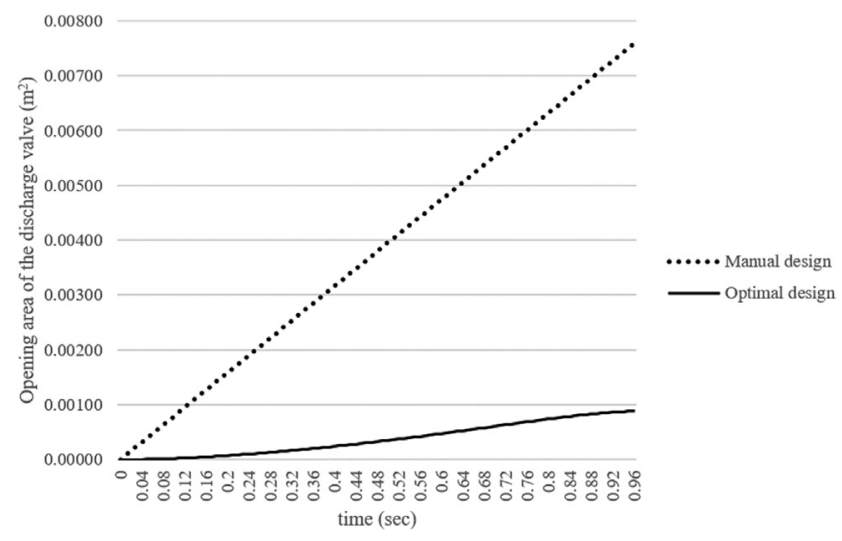

Fig. 6. Opening profile of the discharge valve of the manual and optimum designs.

Table 7. Comparison of objective functions between manual and optimum designs.

\begin{tabular}{lll}
\hline Objective functions & Manual design & Optimization \\
\hline $\max \left(a_{p r}\right)$ & $25.45 \mathrm{~m} / \mathrm{s}^{2}$ & $24.31 \mathrm{~m} / \mathrm{s}^{2}$ \\
$V_{0}$ & $0.1078 \mathrm{~m}^{3}$ & $0.0458 \mathrm{~m}^{3}$ \\
\hline
\end{tabular}

$\max (\Delta P)<0.6[M P a]$

The discharge valve must be opened in a suitable area. The slope of the discharge valve-opening profile formulated in this study must be positive.

$\frac{d\left(S_{v}\right)}{d t}>0$

\subsection{Optimization algorithm}

Many optimization algorithms are available for solving the optimization problem $[12,13]$. However, as the mathematical model of the discharge system comprises nonlinear equations and computes stiff results, we need to use the algorithm to find the global optimum. GA [14] is a commonly used algorithm for the optimization problem. Among the various variations of a GA, we used the NSGA-II algorithm to solve the multi-objective optimization problem. The NSGA-II algorithm is a type of multiobjective optimization algorithm and an improved algorithm for the non-dominated sorting GA [15], which is suitable for solving the stiff optimization problem in this study.

\subsection{Optimization result using the mathematical model}

The optimization results are compared with the manual results, which are the empirically designed values before the optimization process. The optimization results obtained through the described method are as follows. For the manual design, there are no points of discharge valve-opening profile because the valve-opening profile is linear.

Table 6 shows the design variables of the manual and optimum designs. The values of the design variables decreased overall. Fig. 6 shows the discharge valve-opening profile of the manual and optimum designs.

As shown in Fig. 6, the opening profile of the manual design was linear. We assumed that the profile is a form of a curve and optimized it. In the case of a profile having the form of a curve, it is possible to design a discharge system with a smaller opening area while satisfying all constraints. Through optimization, the maximum opening area of the discharge valve decreased from $7.900 \times 10^{-3}$ $\mathrm{m}^{2}$ to $1.000 \times 10^{-3} \mathrm{~m}^{2}$.

Table 7 shows an improvement in the objective functions of the optimum design compared to the manual design. The maximum projectile acceleration $\left(\max \left(a_{p r}\right)\right)$ and maximum volume of the accumulator $\left(V_{0}\right)$ are both decreased, where $\max \left(a_{p r}\right)$ decreased from $24.45 \mathrm{~m} / \mathrm{s}^{2}$ to $24.29 \mathrm{~m} / \mathrm{s}^{2}$ and $V_{0}$ decreased from 0.1078 $\mathrm{m}^{3}$ to $0.0458 \mathrm{~m}^{3}$. This has the effect of reducing the system volume occupied while satisfying system performance. Table 8 shows the constraints of the manual and optimum cases. We can confirm that the optimum design satisfies all constraints.

\section{Surrogate modeling of the underwater discharge system}

Surrogate modeling is used in fields such as model approximation, design space exploration, problem formulation, and optimization [16]. In this study, we solved this problem using a surrogate

Table 8. Comparison of constraints between manual and optimum designs.

\begin{tabular}{llll}
\hline Constraints & & Manual design & Optimization \\
\hline Discharge speed & $>11 \mathrm{~m} / \mathrm{s}$ & $11.30 \mathrm{~m} / \mathrm{s}$ & $11.07 \mathrm{~m} / \mathrm{s}$ \\
$\begin{array}{l}\text { Maximum pressure } \\
\text { difference }\end{array}$ & $<0.6 \mathrm{MPa}$ & $0.5274 \mathrm{MPa}$ & $0.2360 \mathrm{MPa}$ \\
$\begin{array}{l}\text { Maximum projectile } \\
\text { acceleration }\end{array}$ & $<8 \mathrm{~g}\left(=78.4 \mathrm{~m} / \mathrm{s}^{2}\right)$ & $24.45 \mathrm{~m} / \mathrm{s}^{2}$ & $24.31 \mathrm{~m} / \mathrm{s}^{2}$ \\
\hline
\end{tabular}




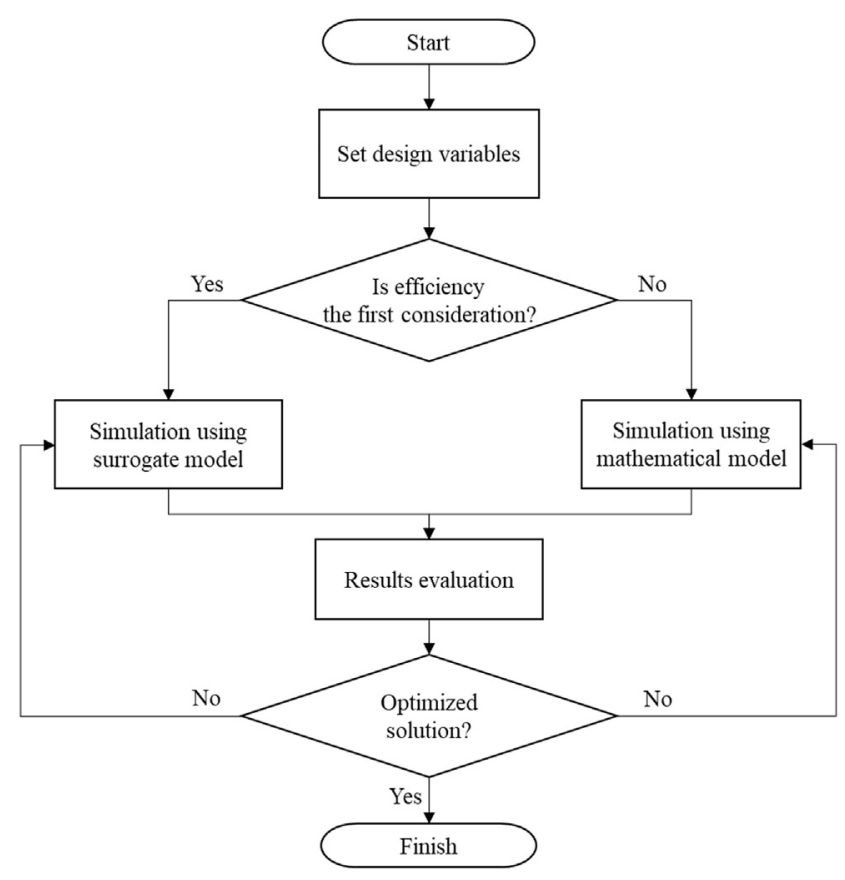

Fig. 7. Process for the optimum design of the underwater discharge system.

model for model approximation, to reduce the computation cost of the complicated discharging simulation and to find an optimum solution in a short time. Because of this, we generate a surrogate model that predicts the results quickly. In this study, linear regression, three types of RBF, and four types of ANNs were used to generate surrogate models. Surrogate models are pre-trained and were called when used for optimization.

\subsection{Optimization process using the surrogate model}

The process for optimizing the design of the discharge system using both mathematical and surrogate models is shown in Fig. 7. In the case of optimization using the surrogate model, the calculation speed improves but certain accuracy loss is inevitable. Hence, the surrogate model is suitable when an engineer intends to improve the optimization speed with some loss of accuracy.

Fig. 8 shows the method of training the surrogate model and optimization process using the surrogate model. The surrogate model is constructed based on the simulation results obtained using a mathematical model. When the simulation is performed, the design variables and simulation results are stored in a database. Once sufficient data have been stored, training is started. If the accuracy is within an acceptable range, the surrogate model is finally obtained. Then, the surrogate model is used instead of the mathematical model during the optimization.

In the case of "black-box" surrogate models, such as RBF or ANNs, the sampling method for building a dataset has no significant effect on the results [16]. Therefore, we used the simulation results obtained during the optimization process as a dataset. In this study, 5000 simulation results with randomly selected design variables were used. The dataset was divided into validation data and training data; $30 \%$ of the dataset was used for validation, and the rest was used for training.

\subsection{Surrogate modeling equations}

To increase the accuracy of the surrogate model, we must select the best regression equation. In this study, three types of regression equations were tested: linear regression, RBF networks, and ANNs.

First, linear regression is the most straightforward and well-known regression technique. It is a method of modeling a regression equation using a linear function, which predicts the relationship between the output $y$ and the independent variables $x_{i}$ [17]. The prediction results obtained through the model take the following form:

$y=a_{0}+a_{1} x_{1}+a_{2} x_{2}+\ldots a_{m} x_{m}$

Second, RBF is a function that predicts the result with a combination of kernel function and weight. It is used for function approximation, timeseries prediction, classification, and system control. $\mathrm{RBF}$, known as kernel-based regression, is a type of simple neural network that uses kernel functions. Each element of the RBF is combined in the following form to calculate the result:

$y(x)=\sum_{i=1}^{N} \omega_{i} \phi(r)$

$r=|| x-x_{i}||$

In Eq. (28), $\omega_{i}$ is the weight, $\phi$ is a kernel function, and $\| x-x_{i}||$ is the distance from the center. We used seven design variables as variable $x$ and each objective function as variable $y$. The center $x_{i}$ was determined to minimize the error by changing the value. The result of the RBF is a combination of kernel functions calculated using the distance from the center. In this study, the following three types of kernel functions were used:

$\phi(r)=r^{k}$ 
1. Generation of surrogate model

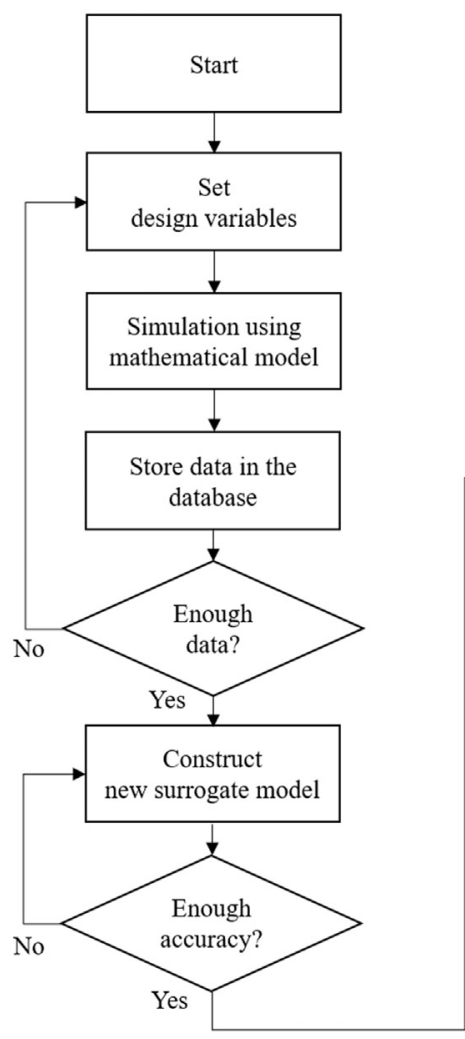

2. Optimization process

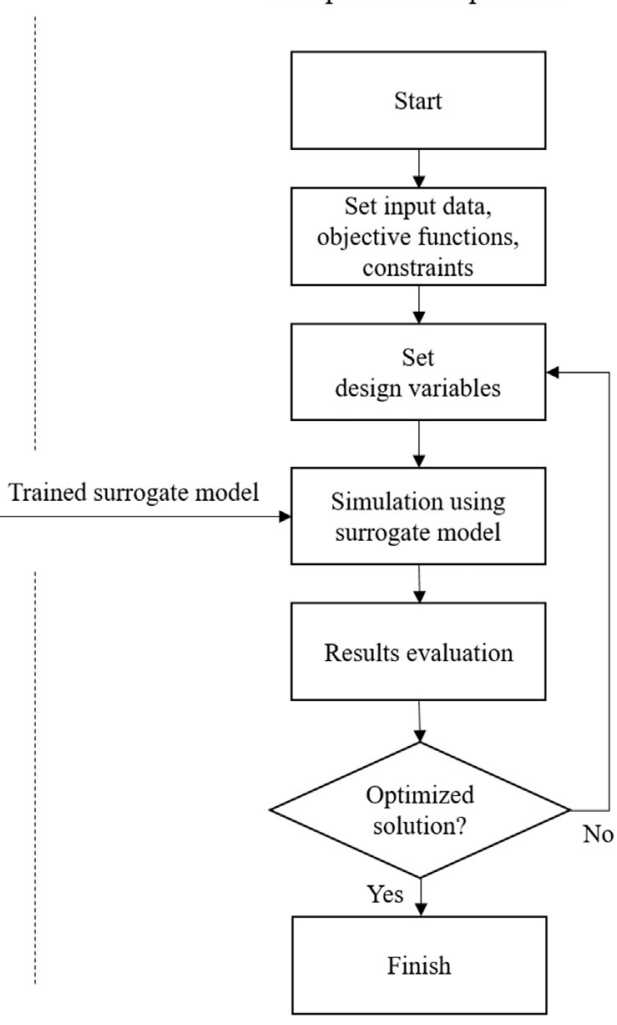

Fig. 8. Training surrogate model and optimization process using the surrogate model.

$\phi(r)=e^{-(\epsilon r)^{2}}$

$\phi(r)=\sqrt{1+(\epsilon r)^{2}}$

Eq. (30) is a polyharmonic kernel function, Eq. (31) is a Gaussian kernel function, and Eq. (32) is a multiquadric kernel function. In Eqs. (29)-(31), $\epsilon$ and $\delta$ are constants, and $\omega_{i}$ can be calculated using the following method [18].

$\phi_{i j}=\phi\left(\left\|x_{j}-x_{i}\right\|\right)$

$$
\left[\begin{array}{llll}
\phi_{11} & \phi_{12} & \cdots & \phi_{1 N} \\
\phi_{21} & \phi_{22} & \cdots & \phi_{2 N} \\
\vdots & & \ddots & \vdots \\
\phi_{N 1} & \phi_{N 2} & \cdots & \phi_{N N}
\end{array}\right]\left[\begin{array}{l}
\omega_{1} \\
\omega_{2} \\
\vdots \\
\omega_{N}
\end{array}\right]=\left[\begin{array}{l}
b_{1} \\
b_{2} \\
\vdots \\
b_{N}
\end{array}\right]
$$

Eq. (33) is established using the given input data $x_{j}$ and output $b_{j}$. The dataset proposed in Section 4.2 is used for input data $x_{j}$ and output $b_{j}$. The following equation can be obtained by calculating the inverse of $\phi_{i j}$ matrix using the following equation:

$$
\left[\begin{array}{l}
\omega_{1} \\
\omega_{2} \\
\vdots \\
\omega_{N}
\end{array}\right]=\left[\begin{array}{llll}
\phi_{11} & \phi_{12} & \cdots & \phi_{1 N} \\
\phi_{21} & \phi_{22} & \cdots & \phi_{2 N} \\
\vdots & & \ddots & \vdots \\
\phi_{N 1} & \phi_{N 2} & \cdots & \phi_{N N}
\end{array}\right]^{-1}\left[\begin{array}{l}
b_{1} \\
b_{2} \\
\vdots \\
b_{N}
\end{array}\right]
$$

Third, an ANN is a network in which neurons of different layers are connected. Weights are improved during the learning process, and an activation function connects the neurons' weighted inputs and outputs. The ANN was developed from the perceptron proposed by Rosenblatt [19] for pattern recognition. ANNs are used for classification, regression, clustering, and anomaly detection.

In this study, we used the surrogate model with a fully connected ANN for regression to predict the simulation results. A fully connected ANN is a network in which all neurons in each layer are connected to all neurons in the next layer. It is a basic type of neural network and is used to generate a regression model. We used various fully connected ANNs with layers ranging from 10 to 160 neurons. We set two or three hidden layers in 


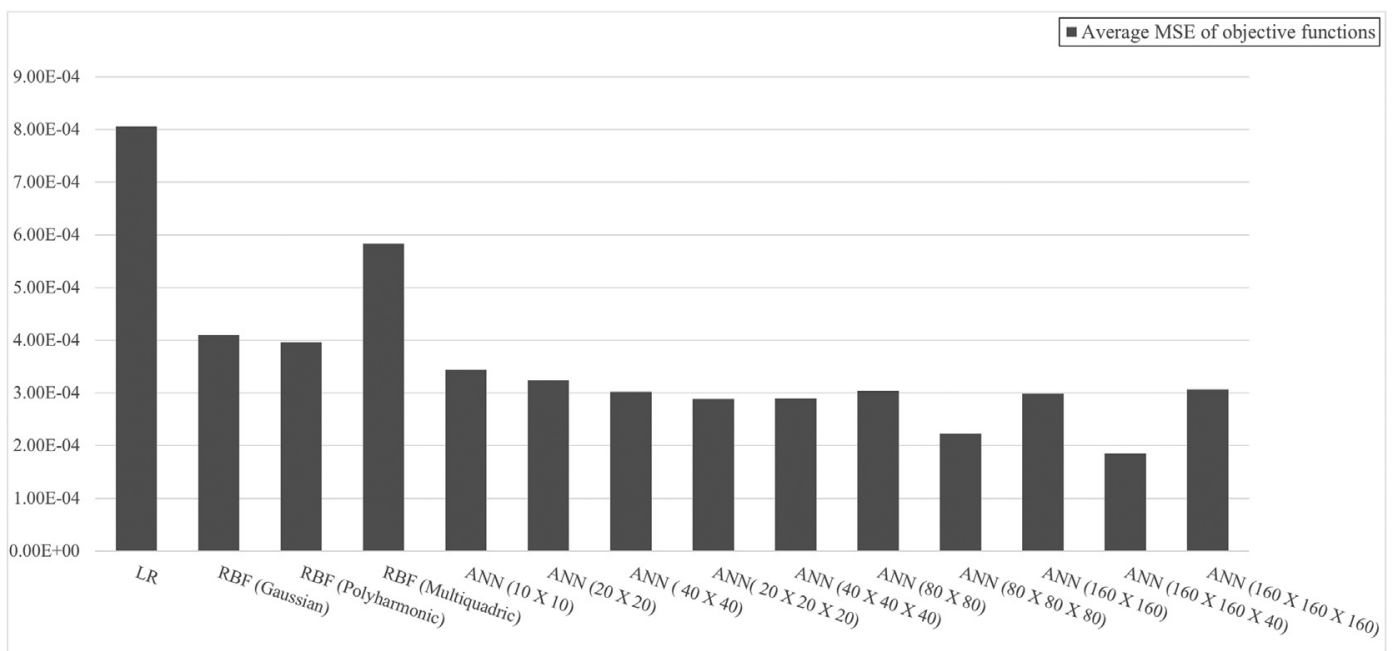

Fig. 9. Average MSE of objective functions calculated using surrogate models.

ANNs, where ReLU was used as an activation function.

The inputs $x_{j}$ are the design variables defined in Table 4 . The outputs $b_{j}$ are the objective functions defined in Table 5 . The dataset, which is explained in Section 4.1, is used to determine the weights of each regression equation.

The criteria for the best regression equation were determined using the function used for validation. In this study, we used the mean-squared error (MSE) to verify the model's accuracy. MSE represents the sample standard deviation of the differences between the measured and predicted values. The MSE was calculated using the following equation:

$M S E=\frac{1}{N} \sum(\text { Measured }- \text { Prediction })^{2}$

The result of MSE is always non-negative, and the closer it is to 0, the better. In Eq. (26), Measured indicates the actual value stored in the dataset, Prediction indicates the value predicted by the surrogate model, and $N$ indicates the number of values.

\subsection{Optimization result obtained using the surrogate model}

Fig. 9 shows the validation results obtained to train the surrogate model before using it for optimization. Linear regression, three RBF networks, and ANNs with different hidden layers and neurons were used.

Tables 9 and 10 show the average MSE of the results. The best model for each method was selected to proceed with the optimization process. We selected the surrogate model for each type with the smallest average MSE. The optimization results of LR, RBF (polyharmonic), and ANN $(160 \times 160 \times 40)$ surrogate models are as follows.

Tables 11 and 12 show the design variables and their errors, of optimum designs compared to the mathematical model. Compared with the optimization result of the mathematical model, $D_{\text {rod }}$ and $V_{2}$ exhibit a relatively large error. The design variables of the ANN $(160 \times 160 \times 40)$ surrogate model have smaller errors compared with the design variables of the mathematical model.

Tables 13 and 14 compare objective functions and their differences between manual and optimum designs. The ANN $(160 \times 160 \times 40)$ surrogate model has the lowest MSE with the mathematical model, on average, at objective functions and design variables. The optimization results obtained by the ANN $(160 \times 160 \times 40)$ surrogate model suggest a better design for the second objective function as compared to the manual design.

Table 15 presents the constraints of the optimum design obtained by the surrogate model. As the model also satisfies the constraints, the ANN $(160 \times$

Table 9. MSE of LR and RBF surrogate models.

\begin{tabular}{lllll}
\hline Surrogate model & LR & RBF (Gaussian) & RBF (Polyharmonic) & RBF (Multiquadric) \\
\hline $\begin{array}{l}\text { Average MSE of objective } \\
\text { functions }\end{array}$ & $8.056 \times 10^{-4}$ & $4.098 \times 10^{-4}$ & $3.959 \times 10^{-4}$ & $5.832 \times 10^{-4}$ \\
\hline
\end{tabular}




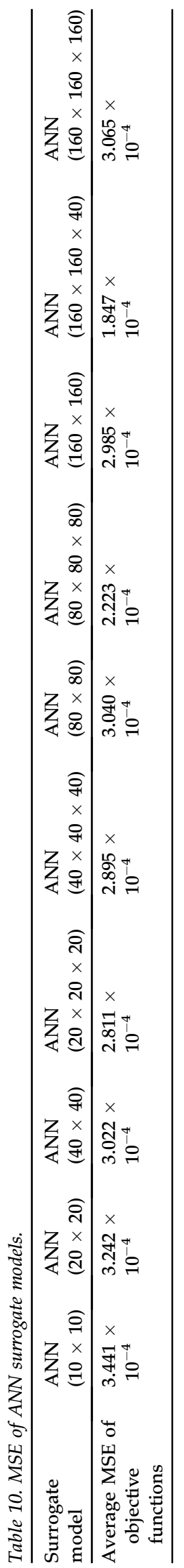

$160 \times 40$ ) surrogate model is the most appropriate surrogate model for optimization.

Table 16 shows the calculation time difference between the mathematical and surrogate models. Using the surrogate model, the optimization results can be obtained in a short time. The mathematical model took $246,611 \mathrm{~s}(68.5 \mathrm{~h})$ to optimize, but the surrogate model took only $490 \mathrm{~s}(0.14 \mathrm{~h})$. This result means that when the design environment or requirements change, the mathematical model takes about $68.5 \mathrm{~h}$ to calculate the optimization result. The surrogate model is relatively inaccurate, but in $\sim 9$ min, a simple optimization result can be obtained. Surrogate models can be used in conjunction with mathematical models to aid engineers in preparing an optimum design in a manner that compensates for the weaknesses of mathematical models.

\section{Conclusions and future work}

When minimizing the volume occupied by an underwater discharge system, there are three primary engineering issues that need to be dealt: reducing the noise and vibration, and satisfying the required performance. To address these issues, design variables were defined to formulate an optimization problem. Each issue was also expressed using objective functions and constraints. As a result of the optimization, the maximum acceleration of the projectile decreased by $4.5 \%$, from $25.45 \mathrm{~m} / \mathrm{s}^{2}$ to $24.31 \mathrm{~m} / \mathrm{s}^{2}$, as compared with the manual design. The maximum volume of the accumulator $\left(V_{0}\right)$ decreased by $57.5 \%$ from $0.1078 \mathrm{~m}^{3}$ to $0.0458 \mathrm{~m}^{3}$. We also studied an optimization method based on the surrogate model to obtain faster results. We used three types of surrogate models to find the best model. As a result, the ANN model with three hidden layers and $160 \times 160 \times 40$ neurons showed the highest accuracy. The prediction with the surrogate model had a $22.36 \%$ error in the first objective function and a $14.19 \%$ error in the second objective function. However, it was 503.2 times faster in the calculation, and it showed the possibility that the proposed method using the surrogate model can be used for complex calculations within a dramatically reduced time.

In the future, the surrogate model will be further developed to improve its accuracy. In this study, we experimented with a limited variety of ANN models. We anticipate the performance of the surrogate model to further improve if ANNs are used. When calculating through a surrogate model, we also plan to predict the time-series data calculated in the simulation. For this purpose, we will develop 
Table 11. Comparison of design variables between optimization by the mathematical model and surrogate models.

\begin{tabular}{lllll}
\hline Design variables & Mathematical model & LR & RBF (Polyharmonic) & ANN (160 $\times 160 \times 40)$ \\
\hline$D_{\text {hydpst }}$ & $0.1500 \mathrm{~m}$ & $0.1500 \mathrm{~m}$ & $0.1500 \mathrm{~m}$ & $0.1519 \mathrm{~m}$ \\
$D_{\text {rod }}$ & $0.1007 \mathrm{~m}$ & $0.1488 \mathrm{~m}$ & $0.0900 \mathrm{~m}$ & $0.1148 \mathrm{~m}$ \\
$D_{p w}$ & $1.100 \mathrm{~m}$ & $1.100 \mathrm{~m}$ & $0.900 \mathrm{~m}$ & $1.038 \mathrm{~m}$ \\
$S_{v 1}$ & $2.020 \times 10^{-5} \mathrm{~m}^{2}$ & $2.090 \times 10^{-5} \mathrm{~m}^{2}$ & $4.815 \times 10^{-5} \mathrm{~m}^{2}$ & $3.027 \times 10^{-5} \mathrm{~m}^{2}$ \\
$S_{v 2}$ & $6.390 \times 10^{-5} \mathrm{~m}^{2}$ & $7.875 \times 10^{-5} \mathrm{~m}^{2}$ & $6.211 \times 10^{-5} \mathrm{~m}^{2}$ & $8.477 \times 10^{-5} \mathrm{~m}^{2}$ \\
$S_{v \max }$ & $1.000 \times 10^{-4} \mathrm{~m}^{2}$ & $1.000 \times 10^{-4} \mathrm{~m}^{2}$ & $1.000 \times 10^{-4} \mathrm{~m}^{2}$ & $1.124 \times 10^{-4} \mathrm{~m}^{2}$ \\
$V_{2}$ & $8.887 \times 10^{-4} \mathrm{~m}^{3}$ & $1.541 \times 10^{-2} \mathrm{~m}^{3}$ & $2.000 \times 10^{-2} \mathrm{~m}^{3}$ & $8.8912 \times 10^{-4} \mathrm{~m}^{3}$ \\
\hline
\end{tabular}

Table 12. Comparison of design variable errors between optimization by the mathematical model and surrogate models.

\begin{tabular}{llll}
\hline Design variables & LR & RBF (Polyharmonic) & ANN (160 × 160 × 40) \\
\hline$D_{\text {hydpst }}$ & $0 \%$ & $0 \%$ & $-1.247 \%$ \\
$D_{\text {rod }}$ & $-47.77 \%$ & $10.60 \%$ & $-13.96 \%$ \\
$D_{p w}$ & $0 \%$ & $18.18 \%$ & $+5.647 \%$ \\
$S_{v 1}$ & $-3.465 \%$ & $-138.4 \%$ & $-20.86 \%$ \\
$S_{v 2}$ & $-23.24 \%$ & $2.804 \%$ & $-6.983 \%$ \\
$S_{v \max }$ & $0 \%$ & $0 \%$ & $-12.42 \%$ \\
$V_{2}$ & $-1634 \%$ & $-2150 \%$ & $-0.2763 \%$ \\
\hline
\end{tabular}

Table 13. Comparison of objective functions between the manual and optimum designs.

\begin{tabular}{llllll}
\hline Objective functions & Manual design & Mathematical model & LR & RBF (Polyharmonic) & ANN (160 $\times 160 \times 40)$ \\
\hline $\max \left(a_{p r}\right)$ & $25.45 \mathrm{~m} / \mathrm{s}^{2}$ & $24.31 \mathrm{~m} / \mathrm{s}^{2}$ & $25.75 \mathrm{~m} / \mathrm{s}^{2}$ & $61.22 \mathrm{~m} / \mathrm{s}^{2}$ & $29.75 \mathrm{~m} / \mathrm{s}^{2}$ \\
$V_{0}$ & $0.1078 \mathrm{~m}^{3}$ & $0.0458 \mathrm{~m}^{3}$ & $0.1121 \mathrm{~m}^{3}$ & $0.0577 \mathrm{~m}^{3}$ & $0.0523 \mathrm{~m}^{3}$ \\
\hline
\end{tabular}

Table 14. Differences in objective functions between manual and optimum designs.

\begin{tabular}{llllll}
\hline Objective functions & Manual design & Mathematical model & LR & RBF (Polyharmonic) & ANN $(160 \times 160 \times 40)$ \\
\hline $\max \left(a_{p r}\right)$ & - & $-4.48 \%$ & $+1.18 \%$ & $+140.6 \%$ & $+16.90 \%$ \\
$V_{0}$ & - & $-57.5 \%$ & $+3.99 \%$ & $-46.48 \%$ & $-51.48 \%$ \\
\hline
\end{tabular}

Table 15. Comparison of constraints between the mathematical and surrogate models.

\begin{tabular}{lllll}
\hline Constraints & & Mathematical model & ANN $(160 \times 160 \times 40)$ & Error \\
\hline Discharge speed & $>11 \mathrm{~m} / \mathrm{s}$ & $11.07 \mathrm{~m} / \mathrm{s}$ & $11.64 \mathrm{~m} / \mathrm{s}$ & $+0.1807 \%$ \\
$\begin{array}{l}\text { Maximum pressure } \\
\quad \text { difference }\end{array}$ & $<0.6 \mathrm{MPa}$ & $0.2360 \mathrm{MPa}$ & $0.2873 \mathrm{MPa}$ & $-4.746 \%$ \\
$\begin{array}{l}\text { Maximum projectile } \\
\text { acceleration }\end{array}$ & $<8 \mathrm{~g}\left(=78.4 \mathrm{~m} / \mathrm{s}^{2}\right)$ & $24.31 \mathrm{~m} / \mathrm{s}^{2}$ & $29.75 \mathrm{~m} / \mathrm{s}^{2}$ & $-3.743 \%$ \\
\hline
\end{tabular}

Table 16. Comparison of calculation time between the mathematical and surrogate models.

\begin{tabular}{ll}
\hline Type of model & Calculation time (s) \\
\hline Mathematical model & $246,611(68.50 \mathrm{~h})$ \\
Surrogate model (ANN & $490(0.14 \mathrm{~h})$ \\
$160 \times 160 \times 40)$ & \\
\hline
\end{tabular}

a surrogate model that can estimate the time-series data to aid the optimization process.

\section{Acknowledgments}

This work was partially supported by the Research Institute of Marine Systems Engineering of Seoul National University, Republic of Korea.

\section{References}

[1] Wang Y. Research on the theory of hydraulic balance system for energy accumulated torpedo launching device. Underwater Weapon 2001;2:42-6.

[2] Tian B. Optimization of structure parameters for hydraulic energy accumulated torpedo launching device. Materials Science Forum 2011;704-705:612-8.

[3] Prebeg P, Zanic V, Vazic B. Application of a surrogate modeling to the ship structural design. Ocean Engineering 2014;84:259-72.

[4] Baroutaji A, Gilchrist MD, Smyth D, Olabi AG. Crush analysis and multi-objective optimization design for circular tube under quasi-static lateral loading. Thin-Walled Structures 2015;86:121-31.

[5] Patnaik S, Coroneos R, Guptill J, Hopkins D. Subsonic aircraft design optimization with neural network and regression approximators. Journal of Aircraft 2005;42(5):1347-50.

[6] Mengistu T, Ghaly W. Aerodynamic optimization of turbomachinery blades using evolutionary methods and ANN- 
based surrogate models. Optimization and Engineering 2008; 9(3):239-55.

[7] Gunnu GR, Moan T. An assessment of anchor handling vessel stability during anchor handling operations using the method of artificial neural networks. Ocean Engineering 2017;140:292-308.

[8] Ellis PR. The development of a controllable weapons discharge system for submarines. WARSHIP 91 International Conference on Naval Submarines 1991;3.

[9] Butcher JC. Implicit Runge-Kutta processes. Mathematics of Computation 1964;18(85):50.

[10] HYDAC International. Accumulators-bladder, piston, diaphragm. 2016.

[11] Park IK, Jung CH. Analysis of the dynamic characteristics of the underwater discharge system using a linear pump. Journal of the Korea Institute of Military Science and Technology 2005;8(3):11-7.

[12] Lee KY, Cho SH, Roh MI. An efficient global-local hybrid optimization method using design sensitivity analysis. International Journal of Vehicle Design 2002;28(4):300-17.
[13] Lee KY, Roh MI. An efficient genetic algorithm using gradient information for ship structural design optimization. Ship Technology Research 2001;48(4):161-70.

[14] Goldberg DE. Genetic algorithms in search, optimization, and machine learning. Reading, MA: Addison-Wesley; 1989.

[15] Deb K, Pratap A, Agarwal S, Meyarivan T. A fast and elitist multiobjective genetic algorithm: NSGA-II. IEEE Transactions on Evolutionary Computation 2002;6(2):182-97.

[16] Wang GG, Shan S. Review of metamodeling techniques in support of engineering design optimization. Journal of Mechanical Design 2006;129(4):370.

[17] Draper NR, Smith H. Applied regression analysis 326. New York: John Wiley \& Sons; 1998.

[18] Schwenker F, Kestler HA, Palm G. Three learning phases for radial-basis-function networks. Neural Networks 2001; 14(4-5):439-58.

[19] Rosenblatt F. The perceptron: A probabilistic model for information storage and organization in the brain. Artificial Intelligence: Critical Concepts 2000;2(6):398. 